\title{
Construindo Paisagens Sonoras através da Colaboração em Espaços Públicos
}

\author{
Mauro Amazonas $^{1}$, Thais Castro ${ }^{1}$, Rosiane de Freitas $^{1}$, Bruno Gadelha ${ }^{1}$ \\ ${ }^{1}$ Instituto de Computação - Universidade Federal do Amazonas (UFAM) \\ 69080-900 - Manaus - AM - Brazil \\ \{mauro.jr, thais, rosiane, bruno\}@icomp.ufam.edu.br
}

\begin{abstract}
Striking tones of nature sounds such as those caused by winds, seas, birdsong, car and factory noises, musical composition and even a song on the radio. All this is responsible for local sounds, which are mixed with a huge amount of noise and diverse sounds, giving rise to the "soundscapes" of a place. What is intended in this study is the construction of a soundscape collaboratively through the interaction with sound in public spaces. To achieve this mission, soundscape composers interact with technology designed to deliver this interaction through your mobile devices. In doing so, composers reuse technology, transforming it into a tool that brings the resignification of public space and can transform the environment around them as they wish, thus challenging the traditional way of producing soundscapes.
\end{abstract}

Resumo. Timbres marcantes de sons da natureza como os provocados pelos ventos, mares, canto de pássaros, ruídos produzidos por carros e fábricas, composição musical e até uma música no rádio. Tudo isso é responsável por sonoridades locais, que se mesclam com uma enorme quantidade de ruídos e sons diversos, fazendo surgir as "paisagens sonoras" de um local. O que se pretende nesse estudo é a construção de uma paisagem sonora de forma colaborativa através da interação com o som em espaços públicos. Para alcançar esta missão, os compositores de paisagens sonoras interagem com a tecnologia criada para proporcionar essa interação por meio de seus dispositivos móveis. Ao fazê-lo, os compositores reaproveitam a tecnologia, transformando-a em uma ferramenta que traz a ressignificação do espaço público, podendo transformar o ambiente ao seu redor no que desejar, desafiando assim a tradicional forma de produzir paisagens sonoras.

\section{Introdução}

Uma paisagem sonora pode ser entendida como o ambiente acústico percebido pelos humanos, em seu contexto. O termo foi originalmente proposto por Michael Southworth [Southworth 1967] e popularizado por R. Murray Schafer no final dos anos 60 [Schafer 1977]. Já a paisagem sonora urbana é uma individualidade intrínseca de cada cidade, formada pelos diferentes sons ouvidos [Schafer 1977] e com uma parte emocional que é determinada pela interpretação multi-sensorial que se obtém a partir de seus mais variados componentes [Kang 2007]. Gaspar [GASPAR 2001] faz uma reflexão sobre as paisagens sonoras, relata a experiência com paisagens sonoras distintas, o que evidencia o 
papel da paisagem sonora em conceder identidade ao lugar. As paisagens sonoras são estudadas por diversas disciplinas como: Design Urbano, Artes, Ecologia da vida selvagem e Ciência da Computação [Bento Coelho 2010].

Atualmente, com o crescimento exponencial das grandes e barulhentas cidades, observa-se uma preocupação para a definição de zonas de tranquilidade sonora. Esses espaços públicos reservados para o lazer como praças, parques e jardins podem ser considerados refúgio da vida urbana por serem locais tranquilos. Os espaços públicos urbanos, como parte integrante da cidade, refletem o desenvolvimento urbano e a cultura urbana, por outro lado, conectam-se com o ambiente urbano e o público para formar um sistema "humano-ambiente" [Jiang 2018].

Assim, o espaço das cidades acaba por ser um local bastante explorado pela arte pública de modos distintos. Quando fala-se de arte pública, refere-se às manifestações visuais em centros urbanos ou espaços públicos, que provoquem impacto nas pessoas. A arte pública não se limita a um único gênero, pode acontecer através da dança, teatro, performance ou arte visual, com intuito de disseminar uma mensagem ao público através de diferentes conceitos e representações [Cultural 2019].

A música e os sons são formas de expressão artística que muitas vezes são realizadas nestes espaços públicos. A Sound Art ou Sonic Art (SA) engloba tipos muito diversos de criação baseados na exploração do som seja em combinação com artes mais tradicionais, como pintura e escultura ou com o digital e mídia interativa [Salazar 2019]. Desta forma, a experiência dos usuários em espaços públicos pode ser enriquecida quando esses locais multifuncionais de lazer e artes são mesclados com tecnologia para criar um ambiente ressignificado para as pessoas, que na atualidade devem ser observados por sua multiplicidade funcional e por consequência sua multiplicidade de significados sociais [Edelweiss and Garzon 2017].

Deste modo, este trabalho apresenta uma estudo que visa explorar a construção de paisagens sonoras através da colaboração dos participantes em uma instalação de arte em espaço público. Este faz parte de uma pesquisa a qual seu objetivo principal é analisar e definir um possível modelo de colaboração emergente da interação do público com o som neste tipo de espaço. Embasada nos conceitos de SA, esta instalação permite que as pessoas possam construir uma paisagem sonora totalmente nova e única através de sons usando seus dispositivos móveis. A paisagem sonora resultante das interações com o ambiente também pode ser considerada um produto artístico, uma composição de música eletroacústica aleatória. A principal característica dessa técnica de composição musical é a sua imprevisibilidade que é alcançada pela livre interação dos participantes no espaço público. Isso se encaixa no conceito de arte pública no sentido de que não se tem controle sobre a interação dos usuários no ambiente, e a paisagem construída e música colaborativa resultante é sempre única e imprevisível [Jiang 2018].

\section{Estudos Realizados}

A ideia principal do ambiente proposto, é permitir que os usuários interajam livremente com um espaço por meio de sons a fim de deixar uma marca registrada de sua colaboração para a construção daquela paisagem sonora utilizando seus smartphones. Os sons podem ser de qualquer tipo como: sons da floresta, sons eletrônicos ou pequenas partes de músicas. Nesta pesquisa foram utilizados sons de música eletrônica por proporcionar sons 
variados. O espaço de construção pode ser uma sala ou um espaço público aberto com uma área limitada. Alto-falantes são necessários para reproduzir os sons dos usuários que estão dentro deste espaço. Para isto foram desenvolvidas algumas tecnologias tais como um framework de processamento de som espacializado em tempo real na plataforma Pure Data e uma aplicação para dispositivos Android denominada Compomus a fim de dar suporte aos estudos realizados [Amazonas 2018].

Para alcançar os resultados pretendidos, duas versões (com objetivos diferentes) do app Compomus foram implementadas e estão representadas na Figura 1. A primeira, conhecida como versão JoyStick, permite ao usuário além do controle da reprodução do som, o controle da localização espacial do mesmo. A segunda, denominada versão PlayStop, detecta a presença do usuário no espaço e reproduz seu som escolhido sem nenhuma outra intervenção. A reprodução é encerrada quando o app detecta que o usuário deixou o espaço definido.

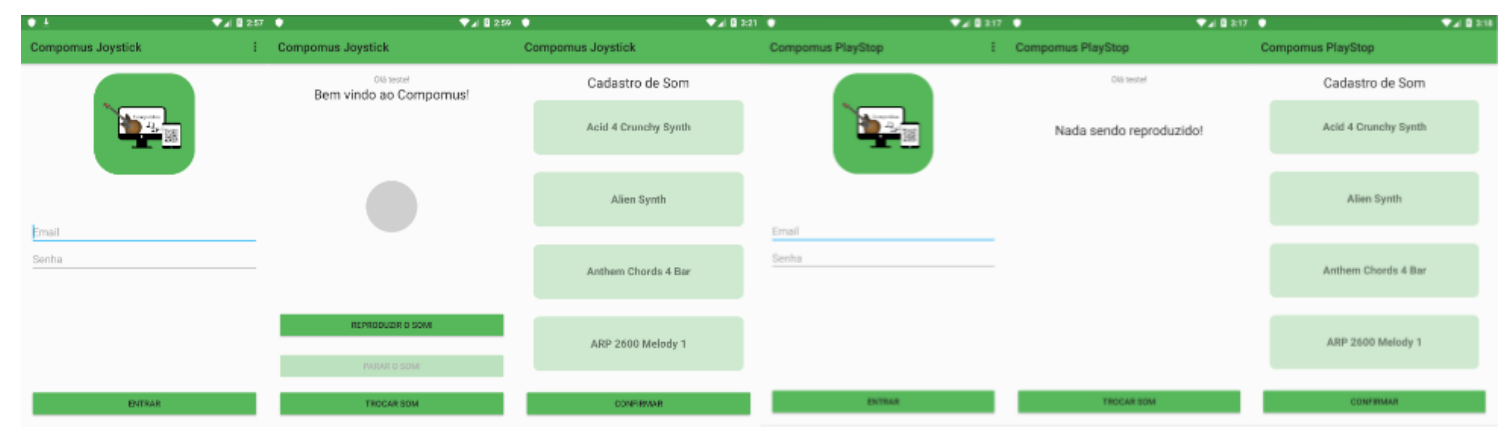

Figura 1. À esquerda versão JoyStick que controla a espacialidade do som e à direita versão PlayStop que detecta a presença do participante automaticamente.

As aplicações possuem três telas, Figura 1, sendo: A primeira de login/cadastro, ao centro as telas principais de controle do som e/ou feedback e por último uma tela para escolha do som a ser reproduzido.

Dois estudos de caso piloto foram realizados com a participação de cerca de 47 alunos voluntários da universidade a fim de estudar a construção de uma paisagem sonora de forma totalmente espontânea, sem nenhuma organização ou papéis previamente definidos. O resultado deste cenário depende exclusivamente da colaboração e interação das pessoas presentes no espaço. Este estudo foi realizado em ambiente experimental, em um local simulando uma instalação de arte em um espaço público Figura 2. Esta metodologia foi utilizada com base na afirmação de Yin [Yin 2015], que defende que o estudo de caso é a metodologia mais indicada para se usar em pesquisas em que as principais perguntas são “como?" ou "por quê?".

Para a realização dos estudos foi reservado um espaço de aproximadamente 36 metros quadrados e os materiais necessários para a instalação e uso da tecnologia são os mesmos relatados em [Amazonas 2017]. Aos participantes foi solicitado que ficassem à vontade para interagir no ambiente como desejassem. As interações dos usuários foram registradas em gravação de áudio e video, no entanto somente imagens podem ser verificadas na página criada para demonstração dos resultados em fotos e áudio [Compomus 2019]. Os usuários puderam utilizar as duas versões do Compomus no ambi- 
ente durante um tempo médio de cinco minutos para cada estudo em que estiveram livres para colaborar ou não.

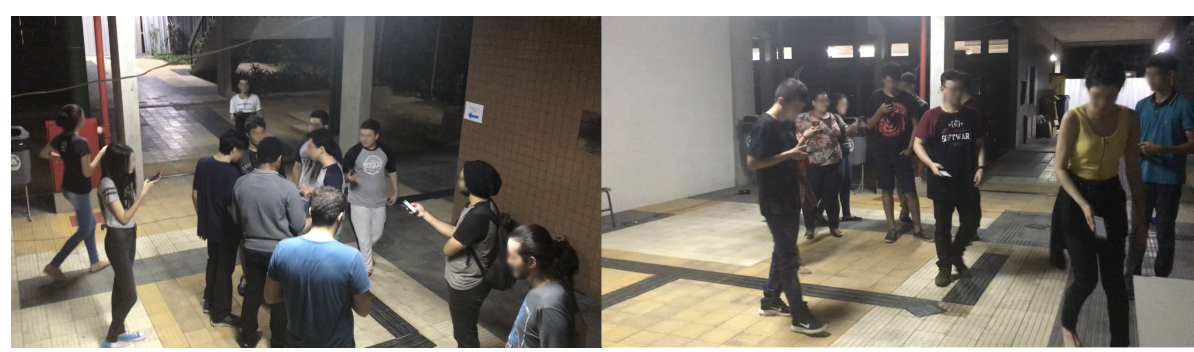

Figura 2. Participantes fazendo uso do App e verificando a movimentação do som.

\subsection{Analisando os resultados}

Para avaliar os resultados obtidos na análise e descobrir se a tecnologia seria bem aceita pelos usuários foi utilizado o modelo Technology Acceptance Model (TAM). Segundo as diretrizes do modelo TAM, foram elaboradas cinco hipóteses para compreender a relação causal entre variáveis externas de aceitação dos usuários e o uso real do computador, buscando entender o comportamento destes usuários através do conhecimento e da facilidade de utilização percebida por eles [Davis et al. 1989]. As hipóteses são:

- H1 - A Utilidade Percebida é afetada quando não há colaboração entre os participantes.

- H2 - A Intenção de Uso é afetada pelas influências culturais.

- H3 - A Facilidade de Uso Percebida proporciona engajamento com a tecnologia.

- H4 - A Utilidade e Facilidade de Uso Percebidas proporcionam uma experiência positiva com a tecnologia mesmo sem conhecimento de conceitos musicais.

- H5 - A habilidade com dispositivos tecnológicos e seus recursos melhora o desempenho pessoal no uso da tecnologia.

Estas hipóteses foram testadas através de questionário aplicado após o uso da tecnologia. Neste caso, um questionário com 30 questões utilizando a escala de Likert [Dalmoro and Vieira 2014] foi desenvolvido de forma que as questões presentes pudessem validar as hipóteses levantadas.

Para se ter uma visão geral de toda interação a partir do uso da versão de exemplo (JoyStick), a Figura 3 lado direito, apresenta todo o registro do caminho percorrido pelos sons dos usuários na paisagem sonora gerada durante o período de cinco minutos. Durante esse período o som foi manipulado pelos usuários e resultou em uma paisagem sonora sensível à localização.

Para maior clareza no exemplo, a Figura 3 lado esquerdo apresenta uma amostra da movimentação do som pela paisagem sonora registrada durante o período de 30 segundos. A disposição das caixas de som seguiram a orientação do plano cartesiano.

Após o estudo, foram verificadas as hipóteses definidas, relacionando estas com as respostas obtidas no questionário aplicado aos participantes dos estudos. Essa análise consistiu na atividade em si, com observação in-loco dos pesquisadores e registro de áudio e vídeo e aplicação do questionário pós-teste sobre a experiência de uso para registrar 

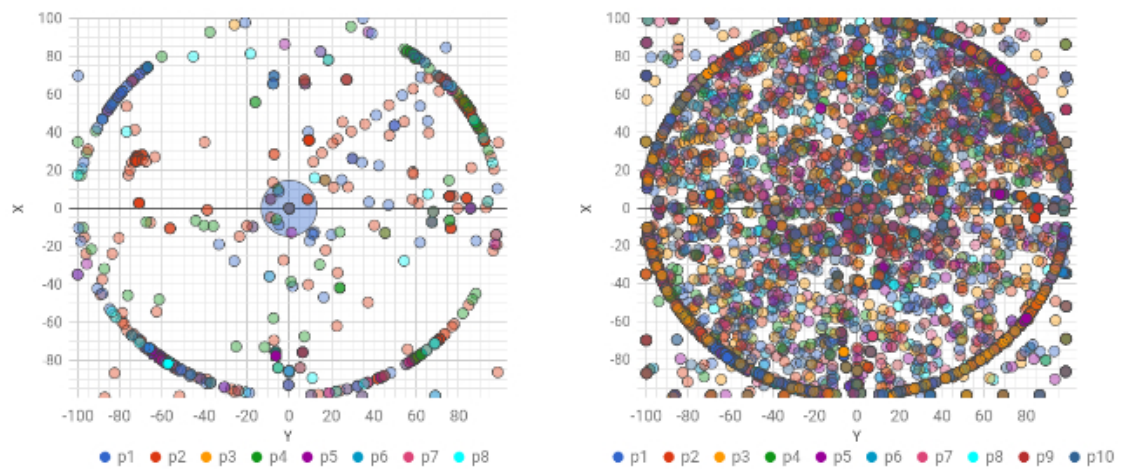

Figura 3. Paisagem sonora obtidas ao longo de trinta segundos no uso da versão JoyStick à esquerda e durante cinco minutos à direita.

impressões dos participantes. Assim, quatro das cinco hipóteses foram confirmadas, e uma delas, a hipótese 2 foi parcialmente confirmada pois esperava-se que os participantes fossem mais heterogêneos em resposta às questões atribuídas à hipótese. Mesmo assim, os resultados evidenciaram uma boa aceitação da tecnologia pelos usuários. Como resultado, dez paisagens sonoras foram geradas. Cinco paisagens foram obtidas através da versão PlayStop e estão disponíveis no sistema estéreo. As outras cinco composições foram obtidas através da versão JoyStick no sistema quadrafônico. Os resultados obtidos foram disponibilizados em um site [Compomus 2019] para que os participantes e os avaliadores deste estudo possam verificar os resultados em áudio das interações para as duas versões do aplicativo Compomus propostas.

\subsection{Problemas encontrados}

Durante a execução dos estudos de caso piloto, percebeu-se que o ambiente artificial que foi considerado acarretou em uma participação não espontânea dos indivíduos. Os participantes eram alunos de uma disciplina ministrada na universidade que foram convidados para o estudo. Sendo assim, percebeu-se que os participantes procuravam "agradar" e que pareciam estar sendo obrigados a participar do estudo tentando sempre seguir as instruções de uso dos pesquisadores. Este tipo de prática dificulta a observação e análise do comportamento dos participantes por parte dos pesquisadores. A execução deste estudo pretende auxiliar na construção de um possível modelo de colaboração que pode emergir a partir das interações entre os participantes e com o espaço.

Com base nestas observações, foram levantadas algumas questões para buscar resolver o problema da participação mandatória do estudo:

- Como mitigar o viés da obrigatoriedade de participação, proporcionando a espontaneidade?

- Como fazer observações e medições em ambiente controlado sem interferir no comportamento do participante?

- Como proporcionar um ambiente propício a colaboração espontânea?

\section{Conclusão}

O objetivo deste estudo é explicitar modelos de colaboração durante a construção de uma paisagem sonora a partir das interações dos participantes com o sons em espaços públicos. 
No entanto, durante a execução dos estudos verificou-se a ausência de espontaneidade dos participantes, o que claramente impede a observação da colaboração de fato. Novos estudos devem ser realizados visando obter dos participantes uma maior espontaneidade. Desta forma, espera-se a colaboração da comunidade para a discussão de novas formas de conduzir os próximos estudos.

\section{Referências}

Amazonas, M. J. B. (2017). Composição musical colaborativa baseada em espacialização sonora em tempo real. Disponível em: https://tede.ufam.edu.br/handle/tede/6111.

Amazonas, M., V. V. B. A. K. G. C. T. G. B. . F. H. (2018). Collaborative music composition based on sonic interaction design. In International Conference on Distributed, Ambient, and Pervasive Interactions, pages 335-346. Springer.

Bento Coelho, J. (2010). A paisagem sonora como instrumento de design e engenharia em meio urbano. Proceedings of the XXIII Encontro da Sociedade Brasileira de Acústica (SOBRAC), Salvador, Brazil, pages 19-21.

Compomus (2019). Media generated from study with compomus playstop and joystick. http://compomus.wixsite.com/compomus. [Online; accessed 10May-2019].

Cultural, E. I. (2019). Arte pública. Arte Pública. Disponível online: http://enciclopedia.itaucultural.org.br/termo356/arte-publica, Acesso em: 12 de Ago. 2019.

Dalmoro, M. and Vieira, K. M. (2014). Dilemas na construção de escalas tipo likert: o número de itens e a disposição influenciam nos resultados? Revista gestão organizacional, 6(3).

Davis, F. D., Bagozzi, R. P., and Warshaw, P. R. (1989). User acceptance of computer technology: a comparison of two theoretical models. Comunicação e Sociedade.

Edelweiss, R. K. and Garzon, M. R. C. (2017). A ressignificação do espaço público de porto alegre a partir da apropriação efêmera da cidade. Revista Prumo, 2(3).

GASPAR, J. (2001). O retorno da paisagem à geografia: apontamentos místicos. Finisterra - Revista Portuguesa de Geografia.

Jiang, T. (2018). Urban public art and interaction design strategy based on digital technology. Cluster Computing, 0123456789:1-8.

Kang, J. (2007). Urban sound environment. Taylor \& Francis, London.

Salazar, C. (2019). What is sound art? https://www.morleycollege.ac.uk/ news / 160 -what-is-sound-art. [Online; accessed 29-May-2019].

Schafer, R. M. (1977). The tuning of the world. Knopf, New York.

Southworth, M. F. (1967). The sonic environment of cities. PhD thesis, Massachusetts Institute of Technology.

Yin, R. K. (2015). Estudo de Caso: Planejamento e Métodos. Bookman editora. 